\title{
Intracellular Outgrowth of the Cell Wall as a Possible Cause of Senescence in Taphrina maculans Butler
}

\author{
U. P. Singh ${ }^{1}$ and Aiko Sakai \\ Biological Laboratories, National Women's University, 630 Nara, Japan
}

Received October 31, 1974

Turmeric (Curcuma longa L.) leaves usually suffer from a serious leaf spot disease caused by Taphrina maculans Butler wherever the plants are grown as spice in India. The infected leaves were collected from the University farm for further study. The ascospores discharged from a single infection spot normally form two types of colonies designated as "salmon-red" and "creamy-white". The salmon-red strain dies with dispigmentation after a few days under optimal nutritional conditions while the white one does not behave so under similar conditions (Pavgi and Upadhyaya 1964). The two strains differ considerably from each other in morphology, cultural behaviour and in genetical make up.

Senescence in some fungi is attributed to the cytoplasmic inheritable character that is manifested by cessation of growth and eventual death of the organism (Marcou 1961, Sermonti 1969, Smith and Rubenstein 1973). The phenotypic expression of the senescence in $T$. maculans is the gradual impediment of growth in both solid and liquid media along with the disappearance of pigment which might start as sector or even otherwise. However, by frequent inoculations from the dying sectors or area, the colony starts further developing with the production of bright red pigment. The creamy-white strain, however, maintains its growth potential without exhibiting any sectorial growth or otherwise development during the continuous growth cycle. The present electron microscopic observations deal with the morphological changes during the senescence in salmon-red strain of $T$. maculans.

\section{Materials and methods}

In order to explore the possible morphological changes in the normal and senescent strains of $T$. maculans, the material was processed for electron microscopy by fixing the spores for $2 \mathrm{hr}$ in a mixture of $3.5 \%$ glutaraldehyde and $2 \%$ paraformaldehyde prepared in phosphate buffer $(\mathrm{pH} 7.4)$ and post-fixed with $1 \%$ aqueous osmium tetraoxide at $\mathrm{pH}$ 7.3. Materials were dehydrated by passing through an ascending concentrations of ethanol and embedded in epoxy resin. Ultra-thin sections were cut with Porter-Blum microtome I and stained with lead acetate for examination under an electron microscope JEM 7.

The extra outgrowth was further characterized chemically following PickettHeaps's method (1967 b). The material was treated with $1 \%$ aqueous periodic acid for $45 \mathrm{~min}$ at room temperature preceded by $2 \%$ sodium bisulphite for $1.5 \mathrm{hr}$

1 Present address: Department of Plant Pathology, Faculty of Agriculture, Banaras Hindu University, Varanasi-221005, India. 
at $60^{\circ} \mathrm{C}$. The material was transferred to $1 \%$ borate buffered hexamine $(\mathrm{pH} 9.2)$ containing $0.1 \%$ silver nitrate for $45 \mathrm{~min}$ at $50^{\circ} \mathrm{C}$. The sections were carefully watched during the later stages of incubation to prevent over-staining. Further treatment with $2 \%$ sodium thiosulphate for about $15 \mathrm{~min}$ was followed by mounting the sections on copper grids.

\section{Observations}

All the observations presented here are based on the electron micrographs of the blastospores of salmon-red cells which undergo senescence under optimal nutritional conditions. After cutting ultra-thin sections of the ovoid spores it is evident that the cell wall starts gradually swelling towards the cytoplasm from an undetermined site (Fig. 1). Swelling appears quite gradual enclosed in the plasmamenbrane exhibiting several fine layers growing inside the cytoplasm. It continues growing further in a lobed fashion after or at the advent of cell germination (Fig. 2). The plasmamembrane extends further with the concomitant deposition of the cell wall material and thus a comparatively bigger globular structure is formed (Fig. 3). Sometimes the growth is flattened pressing the cytoplasm (Fig. 4). Globular structure occasionally exhibits rough surface and a few fibre-like structures projecting into the cytoplasm (Figs. 5, 6). In such cases the plasmamembrane remains invisible. In several cases the globular growth also starts from more than one site in a similar manner (Fig. 7), while excessive outgrowth mostly from one side consuming almost all the cytoplasm is more often observed (Figs. 8, 9). Sometimes the globular growth appears independently in the cytoplasm (Fig. 10). It gradually traverses the nucleus (Fig. 11C). The nucleus degenerates eventually. The continuous swelling of the cell wall finally occupies the entire cell cavity converting it into an electorn opaque mass. Such cells are ultimately devitalized (Fig. 12). The globular growth like a free round body in the cytoplasm is observed only in $0.1 \%$ of the total salmon-red cells observed (about 1000 cells). However, it is not clear whether the round body is part of the outgrowth of the cell wall. Treatment with silver nitrate to determine the chemical nature of the substance exhibits the fine silver grains deposition on the additional outgrowth in the cell suggesting its chemical nature as polysaccharide (Figs. 13, 14).

\section{Discussion}

The salmon-red strain of T. maculans depicts a definite senescence where the pigmented colonies gradually become white owing to the vegetative death of the cells. Distinct radially growing salmon-red colonies exhibit white sectors during senescence which slowly cover the entire circumference, although the dispigmentation also occurs without sector formation. In contrast to this phenomenon, vegetative death in Aspergillus glaucus is usually associated with the excretion of intense brown pigment and the senescent hyphae appear irregular, swollen and highly vacuolated under light microscope (Jinks 1959). Observations on T. maculans under similar optical resolution are in conformity with $A$. glaucus. Frequent inoculations on the 


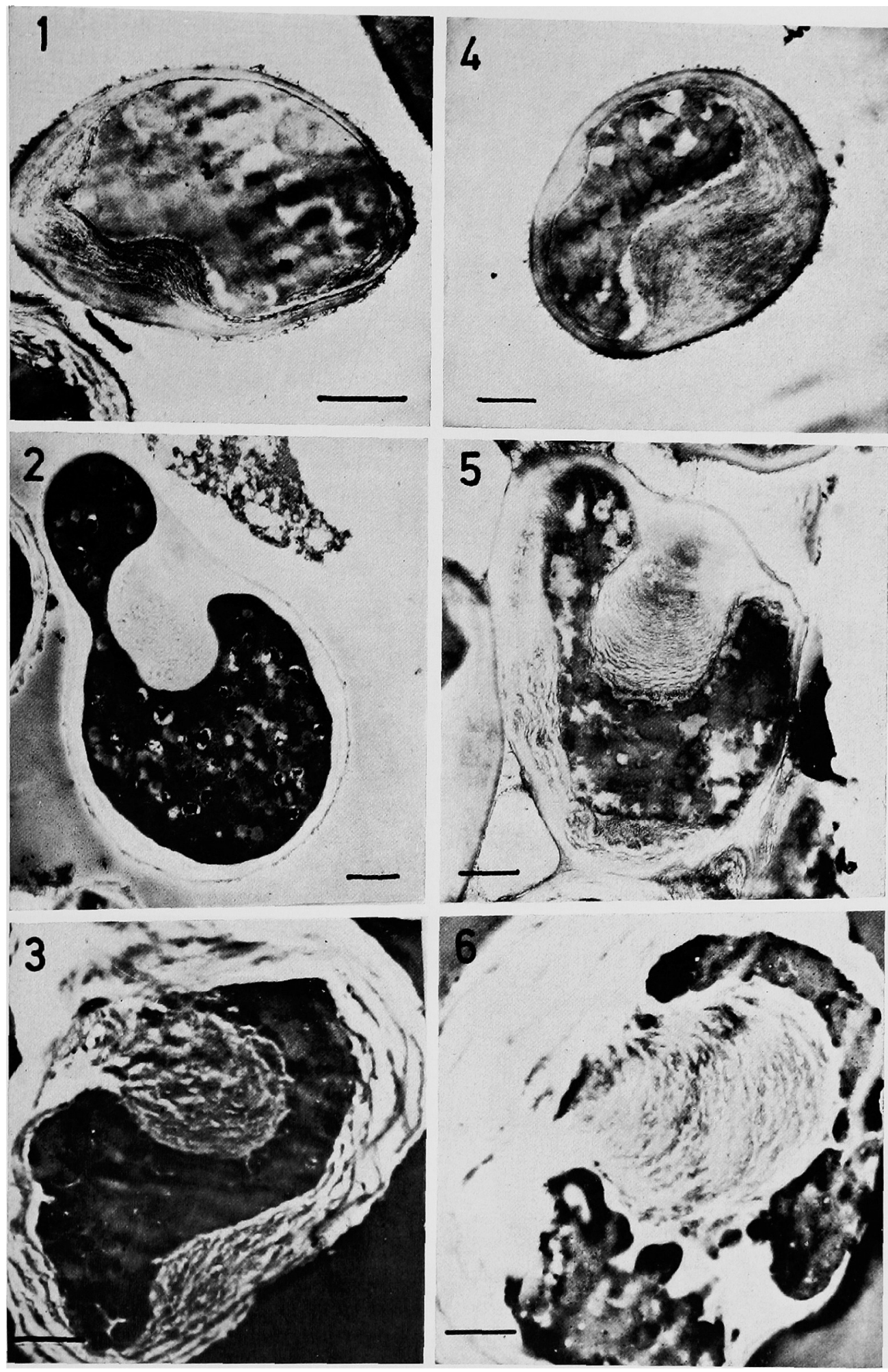

Figs. 1-6. 1, 4, 8, 9. Sequential fibrous swelling of the cell wall in senescent salmon-red cells of Taphrina maculans Butler. 2, 3, 5, 6. Lobed outgrowth of the cell wall projecting into the cytoplasm. Scale $=$ All the bars of figures $1-14=1 \mu$. 

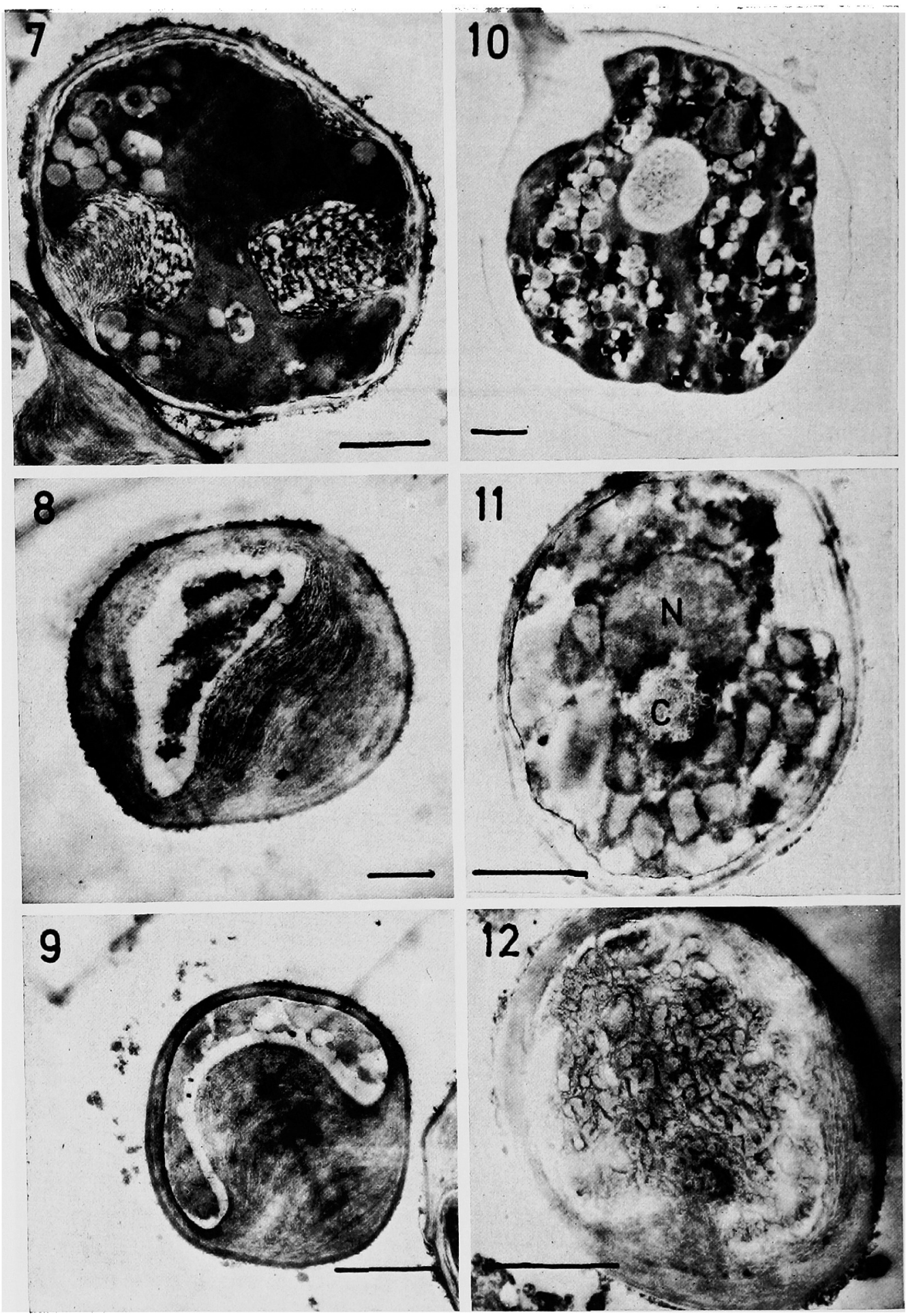

Figs. 7-12. 7-8, lobed outgrowth emanating from more than one sites of the cell wall. 10, development of a round white body independently in the cytoplasm. 11, intracellular outgrowth (C) pressing the nucleus $(\mathrm{N})$. 12, conversion of the entire cytoplasm into an opaque mass resulting into the death of the cell. 
fresh medium revives the colony which suggests that the fungus in culture produces toxin (s) that may be the cause of lethality but such a possibility has been ruled out (unpublished data) in the present studies.

The genetic or biochemical control of the synthesis of the cell wall material and its nonpolarity remains still unexplored. The plasmamembrane probably functions as the protective layer for the globular structure and also serves as the territorial boundary between the outgrowth and the cytoplasm. Its occasional invisibility may be due to the effect of fixatives or any other unknown reasons.

The senescent factor, once thought to be of particulate nature, in some respects resembles a latent viral particled which suddenly shifts to the vegetative state in the aging colony possibly coinciding with a temperate phage or more generally to an episome (Marcou 1961). The experimental data of Smith and Rubenstein (1973) in conjunction with the results of Marcou (1961) indicate that 'senescence' in the vegetative phase of Podospora anserina appears due to a single variant entity in the cytoplasm. In $T$. maculans, although the senescence factor seems to be of particulate nature by the synthesis of intracellular outgrowth that results into the death of the organism, the presence of a viruslike entity or an episome that might be triggering this phenomenon is still unknown. Marcou (1961) earlier put forward several models to account for the senescence in $P$. anserina out of which the present phenomenon resembles her third
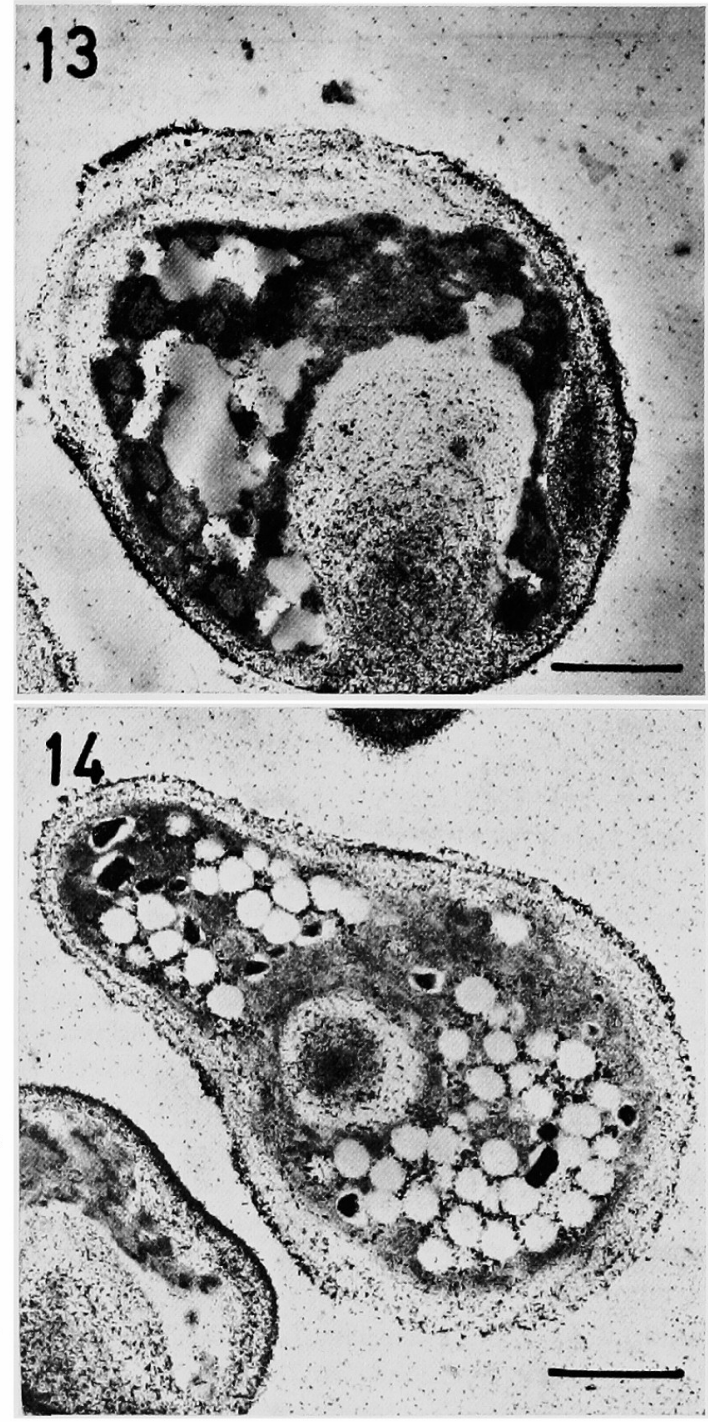

Figs. 13 and 14. Deposition of silver grains on the cell wall and outgrowth suggesting its polysaccharide nature.

model that deals with a self maintaining change occurring in some cytoplasmic structure accounting for the death of the organism. In addition to the Marcou's (1961) models, Holliday (1969) proposed that 'senescence' may result from errors in protein synthesis of the type discussed by Orgel (1963). The present data need further elaboration to explore such a possibility in T. maculans Butler. 


\section{Summary}

Taphrina maculans Butler, a causal agent of leaf spot of turmeric (Curcuma longa L.) forms two types of colonies namely "salmon-red" and "creamy-white". The former strain dies abnormally under optimal nutritional conditions while the latter does not behave so. Electron microscopic observations of both the strains manifest for the first time, an extra intracellular outgrowth from an undetermined site of cell wall that grows further traversing the entire cellular part resulting into the death of the cells. The dead cells become white. The plasmamembrane probably extends further during the synthesis of the extra outgrowth material serving as the boundary wall between the extra outgrowth and the cytoplasm. Such phenomenon of extra synthesis of cell wall material that causes the death of the cell has been observed in the salmon-red strain only.

\section{Acknowledgements}

The senior author (UPS) is highly grateful to the Japan Society for the Promotion of Science for the award of a fellowship and also to Profs. Dr. Susumu Nagai for encouragement and Dr. K. Ueda for his kind permission to work in his laboratory.

\section{References}

Holliday, R. 1969. Errors in protein synthesis and clonal senescence in fungi. Nature (London) 221: $1224-1228$.

Jinks, J. L. 1959. Lethal suppressive cytoplasms in aged clones of Aspergillus glaucus. J. gen. Microbiol. 21: $397-402$.

Marcou, D. 1961. "Notion de longevite et nature cytoplasmique du determinant de la senescence chez quelques champignons". Annales des Sciences Naturalles (Botanique series $12 \mathrm{C}$ ) 2: 653-763.

Orgel, L. E. 1963 . The maintenance of the accuracy of protein synthesis and its relevance to aging. Proc. Nat. Acad. Sci. U. S. 49: 517-521.

Pavgi, M. S. and Upadhyaya, R. 1964. Artificial culture and pathogenicity of Taphrina maculans Butler. Sci. and Cult. 30: 558-559.

Pickett-Heaps, J. D. 1967 b. Preliminary attempts at ultrastructural polysaccharide localization in root tip cells. J. Histochem. Cytochem. 15: 442-455.

Sermonti, G. 1969. Genetics of Antibiotic-producing Organisms. Wiley-Interscience. New York, pp 389.

Smith, J. R. and Rubenstein, I. 1973. The development of senescence in Podospora anserina. J. gen. Microbiol. 76: 283-296. 